\title{
SEVOFLURANE VERSUS PROPOFOL FOR INSERTION OF SUPRAGLOTTIC AIRWAY DEVICES - A COMPARATIVE STUDY.
}

\begin{tabular}{ll}
\hline $\begin{array}{l}\text { Anasthesiology } \\
\text { Kshitish Kumar } \\
\text { Parija* }\end{array}$ & $\begin{array}{l}\text { PG Resident, Department of Anasthesiology and Critical Care, VIMSAR, Burla. } \\
\text { *Corresponding Author }\end{array}$ \\
\hline $\begin{array}{l}\text { Ananta Narayan } \\
\text { Patra }\end{array}$ & PG Resident, Department of Anasthesiology and Critical Care, VIMSAR, Burla. \\
\hline Ankita Rout & PG Resident, Department of Obstetrics and Gynaecology, VIMSAR, Burla. \\
\hline Saswat Satapathy & PG Resident, Department of Pharmacology, VIMSAR, Burla. \\
\hline Sheela Ekka & Assistant Professor, Department of Anasthesiology and Critical Care, VIMSAR, Burla. \\
\hline Ranjan Sahu & PG Resident, Department of Anasthesiology and Critical Care, VIMSAR, Burla. \\
\hline Bidyapati Padhan & PG Resident, Department ofAnasthesiology and Critical Care, VIMSAR, Burla. \\
\hline Lopamudra Panda & PG Resident, Department of Anasthesiology and Critical Care, VIMSAR, Burla. \\
\hline $\begin{array}{l}\text { Pradipta Kumar } \\
\text { Patel }\end{array}$ & Head of Department, Department of Anasthesiology and Critical Care, VIMSAR, Burla.
\end{tabular}

Patel

\section{ABSTRACT}

Background:-A popular method of providing anaesthesia for insertion of SGA device is with the use of bolus intravenous propofol, however it is associated with adverse effects like hypotension, apnoea, and pain on injection. Sevoflurane is a halogenated volatile anaesthetic which satisfies the conditions required for SGA devices insertion without the side effects as seen with propofol.

Objective: - To compare conditions for SGA insertion following anaesthesia with inhalation of sevoflurane or intravenous injection with propofol. Methods: - 128 Patients posted for routine surgeries under general anaesthesia taken as study subject and randomly divided into 2 groups of 64 each. After premedication, Group Preceived intravenous propofol $(2 \mathrm{mg} / \mathrm{kg}$ body weight) with $100 \%$ oxygen via the face mask. In group S, Magills circuit primed with Sevoflurane $8 \%$ in N2O $50 \%$ and $\mathrm{O} 250 \%$ (flow rate $-8 \mathrm{lit} / \mathrm{min}$ ) for 30 seconds connected to the face mask. After Loss of eyelash reflex, SGA insertion was attempted. The time taken from induction of anaesthesia to loss of eyelash reflex, time taken from loss of eyelash reflex to successful SGA insertion and hemodynamic parameters at baseline, at induction and every min for 5 minutes after induction were recorded in both the groups. Data was analysed using student's t-pair test and statistical significance set at $\mathrm{P}<0.05$.

Results:- Successful LMA insertion in first attempt was 100\% in group P with excellent conditions while in group S it was $89.067 \%$ (57 patients) with excellent to satisfactory conditions. Mean arterial pressure was observed statistically significant between the groups $(\mathrm{p}=0.03)$

Conclusion: - Sevoflurane requires greater time for LMA insertion but with better haemodynamic stability. So, it can be used as an alternative.

\section{KEYWORDS}

laryngeal mask airway, propofol, sevoflurane

\section{INTRODUCTION}

A popular method of providing anaesthesia for insertion of supraglottic airway devices is with the use of intravenous (i.v.) propofol which has the advantage of inducing anaesthesia rapidly and depressing upper airway reflexes. However, bolus i.v. propofol has been associated with adverse effects like hypotension, apnoea, and pain on injection. Sevoflurane is a recently introduced halogenated volatile anaesthetic agent with a pleasant odour and low blood gas solubility which allows rapid induction and recovery.

On this background our study was undertaken with a primary aim to compare conditions for supraglottic airway devices insertion following anaesthesia with inhalation of sevoflurane or i.v. induction of propofol. Secondary aim was to compare the hemodynamic parameters such as BP, pulse rate, etc. and side effects if any.

\section{METHODS}

It was a Randomised clinical trial done after due permission of Institutional Ethics committee in Surgery Operation Theatre(OT), O\&G OT, Urology OT of VIMSAR, BURLA, Sambalpur, Odisha. The study population included Patient undergoing short surgical procedures (45-60mins) in different OTs.

The inclusion criteria of patients were

1) Age -18-50yrs

2) Patients of either sex

3) ASA Grade-1 \& 2 with normal preoperative spirometry

4) Patient posted for elective short duration procedures

The exclusion criteria of patients were

1) Anticipated difficult airway

2) Risk of regurgitation, aspiration, full stomach
3) Chronic spine or medical disease

4) Upper respiratory tract infections in past 10 days

5) Morbidly obese patient

The sample size was calculated (Taking effect size 0.5 into consideration).Minimum sample size needed for group $\mathrm{P}$ was found to be 64 and that for group $\mathrm{S}$ was 64 . Simple randomization was done. The demographic characteristics of sample were found. The study tools used were Supraglottic airway (SGA) - Laryngeal Mask Airway (LMA) size 3 and 4.

All the patients were kept fasting for at least 12 hours before induction of anaesthesia. Each patient was given premedication 15 minutes prior to induction of anaesthesia with injection glycopyrollate $(0.004 \mathrm{mg} / \mathrm{kg}$ body wt), injection midazolam $(.04 \mathrm{mg} / \mathrm{kg}$ body wt) and injection nalbuphine $(0.2 \mathrm{mg} / \mathrm{kg}$ body wt). Monitoring consisted of ECG, BP, $\mathrm{SpO} 2$, and ETCO2. Intravenous line was secured and crystalloids were given. Patients were randomized into one of two groups (Group P: Propofol and Group S: Sevoflurane). Both groups received i.v. lignocaine $(2 \mathrm{ml}$ of $1 \%)$ before induction

Prior to the induction of anaesthesia, patients in both groups had a face mask placed over their face and breathing spontaneously. Group P received intravenous propofol ( $2 \mathrm{mg} / \mathrm{kg}$ body weight) with $100 \%$ oxygen via the face mask. In group S, Magill circuit was primed with Sevoflurane $8 \%$ in $\mathrm{N} 2 \mathrm{O} 50 \%$ and $\mathrm{O} 2$ (flow rate $-8 \mathrm{lit} / \mathrm{min}$ ) for 30 seconds. Each patient was asked to exhale maximally and the primed circuit will be then connected to the face mask. They were asked to take vital capacity breaths.

Bispectral index (BIS) value (60) was considered as the point of 
induction in both groups. SGA insertion was attempted by an experienced anaesthesiologist blinded to the insertion technique. The time of induction that is the time (in sec) taken from induction of anaesthesia as per BIS value at 60 , and the time of SGA insertion i.e. time taken (in sec) from attending BIS value 60 to successful SGA insertion will record in both the groups. Grading of conditions IN LMA insertion ${ }^{[1]}$ was followed. Haemodynamic parameters were recorded at baseline, at induction and every min for 5 minutes after induction.

The data was collected on preformed data sheet. The data was managed by using Microsoft Excel. After matching baseline characteristics, all data was analyzed using SPSS Statistics Software. Mean and standard deviation values of all parameters were calculated. Student's paired test was used to compare the values. P value $<0.05$ was considered statistically significant

\section{RESULT}

Table 1: Demographic Data Of The Patients

\begin{tabular}{|l|l|l|l|}
\hline & Sevoflurane & Propofol & P value \\
\hline AGE & $42.55 \pm 8.089$ & $45.19 \pm 5.430$ & 0.669 \\
\hline WEIGHT & $53.20 \pm 7.065$ & $53.61 \pm 6.606$ & 0.791 \\
\hline
\end{tabular}

Quality of LMA insertion was noted with reference to grading of conditions of LMA insertion as shown in table 2.

Table 2: Grading Of Conditions Of LMA Insertion

\begin{tabular}{|l|l|l|l|}
\hline Total Score & Excellent & Satisfactory & Poor \\
\hline sevoflurane & $89.0625 \%$ & $10.9375 \%$ & 0 \\
\hline propofol & $100 \%$ & 0 & 0 \\
\hline
\end{tabular}

Mean induction time group-S and group-P was $116.22 \pm 4.308 \& 88.34$ \pm 7.941 seconds respectively which was statistically extremely significant $(\mathrm{p}<0.0001)$

Table 3: Time Of Induction In Seconds

\begin{tabular}{|l|c|l|l|}
\hline Groups in the study & Mean & N & Std. Deviation \\
\hline sevoflurane & 116.22 & 64 & 4.308 \\
\hline propofol & 88.34 & 64 & 7.941 \\
\hline Total & 102.28 & 128 & 15.371 \\
\hline
\end{tabular}

Mean Pulse Rate and Mean arterial pressure were noted at regular interval as shown in charts 1, 2 respectively. ECG findings and Spo2 remains stable throughout the surgery in both the groups.

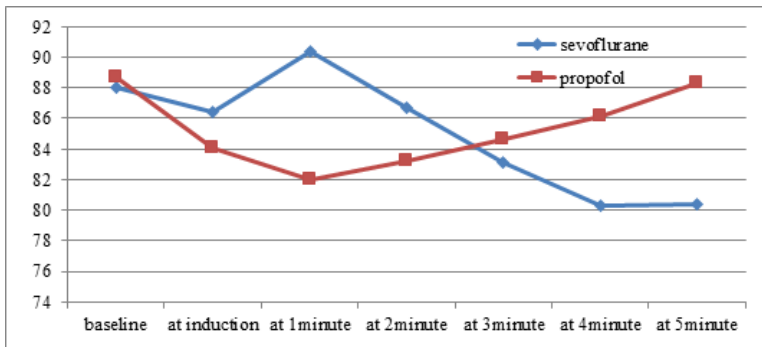

\section{Chart1: Comparison Of Mean Pulse Rate}

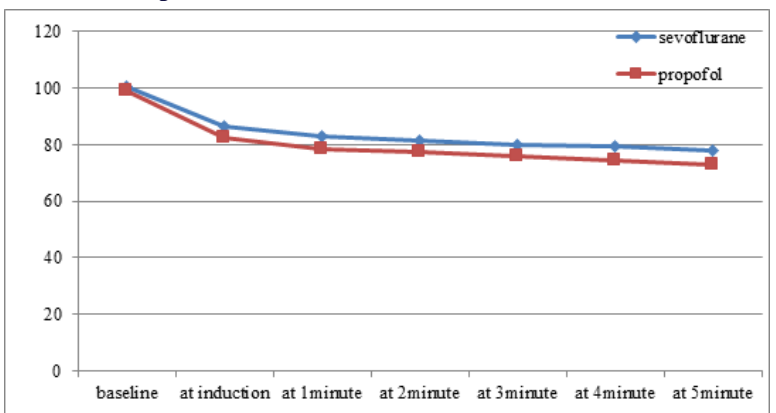

\section{Chart 2: Comparison Of Mean MAP(mm Hg)}

\section{DISCUSSION}

The induction time was longer with sevoflurane than with propofol which was statistically significant, similar to a study by Hall et al and A Thwaites et al ${ }^{[2,3]}$ Mean time taken from start of induction to successful laryngeal mask insertion was significantly shorter $(\mathrm{p}<0.001)$ with propofol (88.34 \pm 7.941 seconds) compared with sevoflurane (116.22 \pm 4.308 seconds) which may due to relaxant action of propofol on jaw muscles while prolonged jaw tightness was associated with sevoflurane which is seen in present study also. ${ }^{[4]}$

Occurrence of complications like coughing, gagging and laryngospasm during LMA insertion were not noticed in both the groups of this study which may be due to adequate depth of anaesthesia with depression of laryngeal reflexes by both agents.

The overall insertion was excellent with propofol with all 64 patients $(100 \%)$ scoring 18 . With sevoflurane, 57 patients $(89.067 \%)$ had excellent conditions for LMA insertion and 7 patients $(10.933 \%)$ had satisfactory conditions. The difference of excellent conditions between the two groups was almost equal to significant level $(p=0.007)$ Lian et al in their study found that more attempts at insertion of LMA were required in patients in sevoflurane group than in propofol group because of inadequate mouth opening. ${ }^{[4]}$ These findings are comparable to our study also. Priya et al found no difference in number of attempts required to insert LMA. ${ }^{[5]}$

\section{LIMITATION}

Sevoflurane expenditure/cost effectiveness is not calculated in the study as it is available free of cost under "Niramaya" programme of Govt. of Odisha. Patient recovery profile is not assessed in the study. OT pollution level is not assessed for the drugs used.

\section{CONCLUSION}

Conditions for LMA insertion provided with intravenous propofol are better than sevoflurane but haemodynamic stability is better with sevoflurane than propofol. So, sevoflurane can be used as an alternative.

\section{ACKNOWLEDGEMENT}

We are thankful to Head of Department, and all the faculties and staffs Department of Anaesthesiology and Critical Care, VIMSAR, Burla for their support.

\section{Conflicts Of Interest: - Nil}

Funding: - No funding sources

Ethical Approval: - The study was approved by the Institutional Ethics Committee.

\section{REFERENCES}

1. Mathur V, Garg D, Jain N, Singhal V, Khare A, Sethi SK A comparative study of propofol and $\mathrm{N} 2 \mathrm{O}$ versus sevoflurane and $\mathrm{N} 2 \mathrm{O}$ with respect to haemodynamic response and ease of laryngeal mask airway insertion: a prospective randomized double blinded study. Int J Res Med Sci 2016;4:3421-6.

2. Hall JE, Stewart JI, Harmer M. Single-breath inhalation induction of sevoflurane anaesthesia with and without nitrous oxide: a feasibility study in adults and comparison with an intravenous bolus of propofol. Anaesthesia. 1997 May;52(5):410-5. doi: 10.1111/j.1365-2044.1997.091-az0086.x. PMID: 9165957.

3. Thwaites A, Edmends S, Smith I. Inhalation induction with sevoflurane: a double-blin comparison with propofol. Br J Anaesth. 1997 Apr;78(4):356-61. doi: comparison with propofol. Br

4. Ti LK, Chow MY, Lee TL. Comparison of sevoflurane with propofol for laryngeal mask airway insertion in adults. Anesth Analg. $1999 \mathrm{Apr} ; 88(4): 908-12$. doi 10.1097/00000539-199904000-00041. PMID: 10195546.

5. V Priya, Divatia JV, Dasgupta D. A comparison of Propofol versus sevoflurane for laryngeal mask airway insertion. Indian Journal of Anaesthesia, 2002, 46(1), 31-34. 